\title{
PLANOS DE EDUCAÇÃO - PROCESSOS, CONDIÇÕES E SITUAÇÕES
}

PLANES EDUCATIVOS - PROCESOS, CONDICIONES Y SITUACIONES

EDUCATION PLANS - PROCESSES, CONDITIONS AND SITUATIONS

\author{
Antonio Bosco de LIMA ${ }^{1}$ \\ Ari RAIMANN ${ }^{2}$ \\ Camila Alberto Vicente de OLIVEIRA ${ }^{3}$ \\ Elizabeth Gottschalg RAIMANN ${ }^{4}$
}

\section{Considerações}

O Grupo de Estudos e Pesquisas sobre o Conselho Municipal de Educação no Brasil, GEP-CMEBr, desenvolve pesquisas, reflexões e debates sobre os Planos de Educação nos seus níveis federal, estaduais e municipais. O grupo reúne investigadores de diversas instituições federais.

Apresentado pela Revista Ibero-Americana de Estudos em Educação (RIAEE), este dossiê traz 10 artigos, seja no formato de ensaio teórico, de revisão bibliográfica, de relato de pesquisas ou de análise documental, cada um com suas características locais e contextuais, enriquecendo esta publicação. Há textos de pesquisadores da Universidad del Magdalena-RUDECOLOMBIA, da Universidade Federal de Goiás/Regional Jataí, Universidade Federal da Grande Dourados-MS, Universidade Federal de Mato Grosso/Campus Araguaia, Universidade Federal de São Carlos/Campus Sorocaba, Universidade Federal de Uberlândia-MG e Universidade de Uberaba - (Uniube), Campus UGD, Uberlândia-MG.

1 Universidade Federal de Uberlândia (UFU), Uberlândia - MG - Brasil. Professor adjunto com Pós-Doutorado (UNICAMP) na área de concentração em Filosofia e História da Educação. Faculdade de Educação (FACED) e Programa de Pós-Graduação em Educação (PPEGED). ORCID: http://orcid.org/0000-0002-3192-0059. E-mail: boscodelima@gmail.com

2 Universidade Federal de Goiás (UFG), Jataí - GO - Brasil. Docente do Programa de Pós-Graduação em Educação. ORCID: https://orcid.org/00000001-6278-2595. E-mail: raimann04@ gmail.com

3 Universidade Federal de Goiás (UFG), Jataí - GO - Brasil. Docente do Curso de Pedagogia e do Programa de Pós-Graduação em Educação. ORCID: https://orcid.org/0000-0002-0614-4481. E-mail: camilaoliveira.ufg@gmail.com

4 Universidade Federal de Goiás (UFG), Jataí - GO - Brasil. Professora de Graduação e Pós-Graduação. Doutorado em Educação (UFU). ORCID: http://orcid.org/0000-0003-4359-5828. E-mail: elizabethraimann@gmail.com 
A investigação que está em andamento dedica-se ao acompanhamento e análise da Implementação e controle social dos Planos Municipais de Educação. Esta pesquisa teve seu início em 2018 e seguirá até 2020. Objetiva-se avaliar em que condições se apresentam os planos, considerando que o PNE (2014-2024) passa por um momento difícil e complexo. Tal situação tem implicações diretas nos planos estaduais e municipais.

Elaborado e publicado o Plano Nacional de Educação, pela promulgação da Lei n. ${ }^{\circ}$ 13.005/ 2014, os municípios, os Estados e o Distrito Federal, receberam a incumbência de avaliar e acompanhar passo a passo a implementação dos seus respectivos planos de educação. Segundo a lei o "seu cumprimento é objeto de monitoramento contínuo e de avaliações periódicas realizadas pelo Ministério da Educação (MEC), pelas comissões de educação da Câmara e do Senado, pelo Conselho Nacional de Educação (CNE) e pelo Fórum Nacional de Educação" (BRASIL, 2014, p. 8).

Nesse contexto, os processos de avaliação e monitoramento dos planos de educação revelam grande diversidade de perspectivas, visto que eles estão colocados em condições econômicas e políticas diferentes, embora muito semelhantes em cada espaço/tempo. Os enfoques dados objetivam mostrar a riqueza de possibilidades e de olhares diante de objetos tão importantes para a sociedade brasileira, especialmente para a classe trabalhadora, pensando no direito à educação de qualidade socialmente referenciada.

O dossiê: "Planos de educação - processos, condições e situações" objetiva oportunizar reflexões ampliadas a respeito da temática, considerando os diversos interesses políticos nele envolvidos, tendo isso repercussão no projeto de nação que se quer desenvolver. Por outro lado, a contribuição da análise de uma proposta educacional voltada aos interesses de um determinado povo, no caso Wayuu, na Colômbia, aponta para a pluralidade étnica presente em um território nacional e que, nesse caso, isso deveria se levado em conta ao se propor uma política de educação nacional.

O primeiro texto, de Paulo Gomes Lima, "O planejamento da educação brasileira (PNE 2001-2014)", discute as relações entre o planejado (metas e estratégias) à luz dos Planos Nacionais de Educação do Brasil (PNE 2001-2010; 2014-2024) e os anseios da sociedade civil, tendo como eixos transversais a democratização do acesso e a universalização de educação para todos. O autor faz uma abordagem qualitativa dos dados, que apontam "um descompasso entre metas previstas, metas alcançadas (ainda que parcialmente, no caso do segundo PNE ainda em vigência) e a não cobertura ou observância das solicitações demandadas pelos cidadãos brasileiros." 
Por sua vez, com o texto: “A gestão educacional nos planos de educação: do nacional ao municipal", Andréia Vicência Vitor Alves, Andrêssa Gomes de Rezende Alves e Elis Regina dos Santos Viegas analisam a gestão educacional nos Planos de Educação, com destaque para os Planos Nacionais de Educação (2001-2011 a 2014-2024) que norteiam a elaboração e implementação dos Planos Estaduais e Municipais de Educação. A partir de pesquisa bibliográfica e documental, as autoras constatam que "a elaboração ou adequação dos Planos Estaduais e Municipais de Educação não expressou alterações consideráveis em relação às suas especificidades e a maioria deles apresenta uma reescrita da meta 19 do PNE (2014-2014)". Destacam, ainda, as autoras que: "mesmo sendo prevista a construção dos PEEs e PMEs pelos estados e municípios, considerando as suas singularidades locais, eles não a realizaram no que se refere a gestão democrática”.

O terceiro texto: “Atuação do Conselho de Educação no controle social dos planos decenais", de Maria Alice de Miranda Aranda, Mariclei Przylepa e Elizangela Tiago da Maia, discute o tema do controle social e sua relevância para o desenvolvimento da educação de qualidade como direito social. Apresenta uma análise a respeito da atuação do Conselho de Educação no controle social dos Planos Decenais de Educação. Mostram as autoras que "o planejamento educacional é fundamental para projetar ações que garantam a ampliação do direito à educação com qualidade socialmente referenciada". Esse destaque, no entanto, não garante que o plano seja implementado, sendo necessária a atuação dos Conselhos de Educação nesse processo, em defesa do projeto em favor da sociedade.

Por sua vez, Camila Alberto Vicente de Oliveira e Fernando Silva dos Santos, descrevem e analisam, no artigo seguinte, a tramitação legislativa do PME em um município do interior goiano destacando os embates oriundos nesse processo e as expectativas em torno desse Plano. Intitulado “Tramitação legislativa do Plano Municipal de Educação de Jataí - GO: tensões, embates e perspectivas" e sob orientação teórico-metodológica da análise crítica do discurso, o estudo ocupa-se de análise documental de atas das sessões da Câmara Municipal nas quais foram apreciadas o projeto de lei do Plano de educação e notícias disponíveis na internet acerca desse movimento. Destacam no texto que os documentos revelam pouco das tensões vividas na casa legislativa, mas indicam que esse silêncio oculta projetos e processos em disputa. Frisa-se que apesar de caracterizar uma realidade local, a reflexão empreendida aponta para os (des)caminhos da participação e da gestão democrática os quais são recorrentes na política educacional brasileira em todos os níveis.

Na sequência, a partir de uma proposta de educação popular, o texto de Gercina Santana Novais e Tiago Zanquêta de Souza em “A elaboração do Plano Municipal de 
Educação: experiência de educação popular?" objetiva contribuir para a reflexão sobre a elaboração do Plano Municipal de Educação de Uberlândia/MG (2015-2025). Os autores orientados pela concepção, valores, princípios e metodologias da Educação Popular, embasados nos conceitos de Educação Popular, participação democrática, saber da experiência feito e resistência propositiva popular, apresentam elementos para a compreensão do planejamento da educação vinculado a uma proposta de educação para a emancipação e para a humanização. Para isso analisam uma experiência relativa à elaboração do PME do município tendo como referência a construção da escola pública, democrática, popular, laica, gratuita e gestada em rede.

O sexto texto traz uma análise do trabalho docente no contexto do Plano Municipal de Educação de em um município no interior de Goiás. Ari Raimann e Rosângela Henrique da Silva Farias discutem tensões que envolvem o trabalho docente, visto que não há como desvincular as políticas públicas educacionais no município do trabalho docente. Desse modo, com base em pesquisa documental, os autores exploram documentos oficiais do município que afetam diretamente o trabalho docente, notadamente o Plano Municipal de Educação - o proposto e o aprovado - e o Estatuto do Magistério. Desse modo, “o Plano Municipal de Educação e o trabalho docente sob tensões". Os autores concluem que a prioridade nas políticas é dada aos índices de avaliação em larga escala, em detrimento da valorização do trabalho docente.

Considerando também importante o debate sobre a carreira docente, Odorico Ferreira Cardoso Neto e Egeslaine de Nez em "Plano Municipal de Educação (PME): valorização e desafios da carreira docente" buscam analisar o plano municipal de Barra do Garças/MT, em vista das metas do plano nacional e estadual, nos termos que dizem respeito à valorização da carreira docente. A pesquisa bibliográfica e documental, com abordagem crítica de análise dos dados, elucida que a ação governamental em Barra do Garças necessita priorizar e potencializar os investimentos em educação em vista de sua função precípua ligada ao atendimento da Educação Infantil e do Ensino Fundamental. Os dados analisados identificam que isso não vem acontecendo. Neste sentido, é imprescindível o desenvolvimento de políticas que tenham como prioridade não só a valorização do magistério, visando evitar o declínio da profissão, mas que as pessoas que optem pela docência sejam de fato assistidas em sua valorização profissional.

O oitavo texto, cuja abordagem é a avaliação e monitoramento do Plano Municipal de Educação do município de Jataí/GO, tem como autora Elizabeth Gottschalg Raimann, sendo o título “Avaliando o Plano Municipal de educação: monitoramento e controle social”. 
Objetiva analisar as ações do Conselho Municipal de Educação e da Secretaria Municipal de Educação, considerando o monitoramento e a avaliação do Plano Municipal de Educação (PME), que culminaram na Conferência Municipal de Educação no município Jataiense. A pesquisa documental problematizou as categorias monitoramento e controle social no contexto do Estado gerencial. Na análise, a autora pondera que o processo de implementação e avaliação do PME se apresenta, na aparência, de forma democrática, porém, na sua essência objetiva a responsabilização dos envolvidos. Por outro lado, o controle social que conta com a participação da sociedade no processo de monitoramento e avaliação do PME almeja uma qualidade socialmente referenciada.

O nono texto se ocupa de trazer "Teses sobre a educação municipal e o Conselho Municipal de Educação no Brasil”, no qual Antonio Bosco de Lima trabalha, de modo muito instigante, com teses que enfocam a participação e o papel mobilizador dos Conselhos Municipais de Educação (CME). No artigo, o autor aborda o papel dos Conselhos desde sua origem, apresentando sete teses sobre a perspectiva de democratização do CME. As referidas teses são seguidas de "antíteses e indicando ao leitor a tarefa de fazer uma reflexão quanto às respectivas sínteses". Conclui que a autonomia dos CMEs está relacionada a "um projeto coletivo de sociedade justa e igualitária, o que implica ter acesso aos bens materiais, sociais, culturais, econômicos e políticos".

E, por fim, uma contribuição de pesquisadores do grupo de investigação Calidad Educativa en un Mundo Plural CEMPLU de la Universidad del Magdalena, Colômbia, com o texto "Wayunkeera, un trenzado metodológico epistémico del desarrollo humano WAYUU como un anclaje a la metodología propia”, dos autores Gabriel Segundo Iguarán Montiel, Iván Manuel Sánchez Fontalvo e Jennifer Tatiana Ortiz Segrera. A abordagem traz uma proposta educacional, com metodologia específica, voltada aos princípios étnicoculturais da comunidade WAYUU fundamentada em uma prática de vida que considera a sua língua materna. Nesse caso, a palavra Wayunkeera incorpora uma pedagogia específica, fundamental para a sobrevivência de seu povo, incorporando o ser/cosmos/natureza, fatores inseparáveis que traduzem o modo de ser e viver do povo WAYUU.

Refletir sobre os planos de educação tem como premissa central a ideia de que o planejamento e a execução de políticas educacionais devem ficar sob a responsabilidade dos atores que constroem a escola e educação públicas e não sob a égide do poder político. Defende-se, portanto, a gestão democrática e participativa a qual pode ter nos Conselhos a função de mediação entre os diferentes entes de modo a garantir que as necessidades e expectativas dos usuários e profissionais da educação sejam contemplados. 
Os planos - nacional, estaduais e municipais - fundamentam-se na tríade diagnóstico, planejamento e execução/monitoramento e, nesse sentido, esse dossiê ocupa-se do exercício teórico de compreender esses processos em diferentes contextos, condições e situações. Considera-se que a participação e a mobilização sociais como condição sine qua non para garantir o atendimento àquilo que se espera do objeto planejado.

Genuíno Bordignon (2014), em seu texto 'Caminhar da educação brasileira: muitos planos, pouco planejamento', parte do poema "Para que serve a utopia", de Eduardo Galeano, para fazer uma metáfora com os processos de planejamento. Nas palavras do poeta Galeano

A Utopia está lá no horizonte.

Me aproximo dois passos, ela se afasta dois passos.

Caminho dez passos e o horizonte corre dez passos.

Por mais que eu caminhe, jamais alcançarei.

Para que serve a Utopia?

Serve para isso: para que eu não deixe de caminhar.

A conjuntura política brasileira, igualmente, dialoga com o poema à medida que permite algumas conquistas sociais à classe trabalhadora e, no entanto, há uma tendência histórica à descontinuidade.

Nessa linha, o autor advoga que planejar deve ser entendido como o contrário de improvisar (BORDIGNON, 2014) e, diante disso, o projeto de educação nacional precisa, sobretudo, atender àquilo que se situa na condição de um projeto de Estado.

\section{REFERÊNCIAS}

BORDIGNON, Genuíno. Caminhar da educação brasileira: muitos planos, pouco planejamento. In: SOUZA, Donaldo Bello; MARTINS, Angela Maria (orgs). Planos de educação no Brasil. Planejamento, políticas, práticas. São Paulo: Loyola, 2014. p. 29-53.

\section{Como referenciar este artigo}

LIMA, Antonio Bosco de; RAIMANN, Ari; OLIVEIRA, Camila Alberto Vicente de; RAIMANN, Elizabeth Gottschalg. Planos de educação - processos, condições e situações. Revista Ibero-Americana de Estudos em Educação, Araraquara, v. 15, n. esp. 1, p. 698703, maio 2020. e-ISSN: 1982-5587. DOI: https://doi.org/10.21723/riaee.v15iesp.1.13343

Submetido em: 30/10/2019

Revisões requeridas: 10/11/2019

Aprovado em: 20/12/2019

Publicado em: 30/04/2020 